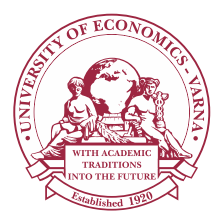

Izvestiya Journal of Varna University of Economics 3 (2021)

IZVEST IYA

Journal of Varna University of Economics

http://journal.ue-varna.bg

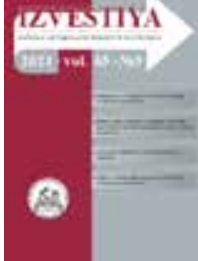

\title{
IMPACT OF COVID-19 \\ ON THE PERFORMANCE OF NIGERIA'S STOCK MARKET
}

\section{Muideen Adejare ISIAKA ${ }^{1}$, Modinat Omolara OGUNMOLU ${ }^{2}$, Lukuman Olalekan LAMIDI ${ }^{3}$, Saheed Timileyin OGUNMOLU ${ }^{4}$}

${ }^{1}$ Department of Economics \& Actuarial Sciences, Crescent University, Abeokuta, Ogun State. Nigeria. E-mail: dr.isiaka@gmail.com

2 Department of Economics \& Actuarial Sciences, Crescent University, Abeokuta, Ogun State. Nigeria. E-mail: modinaomolara@gmail.com

${ }^{3}$ Federal College of Animal Health and Production Technology, Moor Plantation, Apata, Ibadan, Oyo State, Nigeria. E-mail: lamidilukuman42@gmail.com

${ }^{4}$ Department of Economics \& Actuarial Sciences, Crescent University, Abeokuta, Ogun State.

Nigeria. E-mail: saheedtimi11@gmail.com

JEL: G01, G40, G41

Key words:

Covid-19, Stock Market,

All Share Index,

Structural Break, ARIMA

\begin{abstract}
This study identifies the structural break date in the series of All Share Index (ASI) of the Nigeria's capital market using innovational outlier methodology with the Augmented Dickey-Fuller unit root with structural break test. The study also examines the descriptive characteristics and model structure of ASI before and after the identified break date using ARIMA methodology. It uses daily data of ASI from November 27, 2018 to November 24, 2020. The results indicate that the break date is March 6, 2020. The mean results decreased after the break. The series before the break follows ARIMA $(3,1,12)$, while it follows ARIMA $(7,1,9)$ after the break. The diagnostic test revealed that the ARIMA $(7,1,9)$ fails to capture the entire variation in the series. The modified model for post break period is $\operatorname{AR}(7), M A(8)$ and $\mathrm{MA}(9)$ process. However, the estimated volatility of the series decreased after the break. The study recommends that capital market studies and policies going forward should incorporate the impact of Covid-19 induced structural break.

(C) 2021 University of Economics - Varna
\end{abstract}

Citation: ISIAKA, Muideen Adejare, OGUNMOLU Modinat Omolara, LAMIDI, Lukuman Olalekan, OGUNMOLU, Saheed Timileyin (2021) Impact of Covid-19 on the Performance of Nigeria's Stock Market. Izvestiya Journal of Varna University of Economics, 65 (3), pp. 294 - 308.

DOI: 10.36997/IJUEV2021.65.3.294 
Muideen A. Isiaka, Modinat O. Ogunmolu, Lukuman O. Lamidi, Saheed T. Ogunmolu. Impact of Covid-19 on the Performance of Nigeria's Stock Market

\section{Introduction}

Covid-19 is not the first epidemic disease that affects the global economies. The previous ones include the Spanish Influenza of 1918 which resulted in about 40 million deaths. The estimated short term economic loss attributed to the Spanish Influenza between 1918 and 1919 was about $\$ 4$ trillion (Fernandez, 2020). The second notable epidemic was the SARS outbreak in 2002 which also started from China and seriously affected the Asian continent. The human death and estimated economic loss from SARS were 900 people and $\$ 54$ billion respectively (Fernandez, 2020). More recently, Ebola outbreak affected the West Africa sub region between 2013 and 2016. The estimated deaths and economic loss were 11,300 and $\$ 53$ billion respectively (Fernandez, 2020).

The current Covid-19 started in China in December 2019 and was declared as pandemic by WHO on March 11, 2020. It has caused serious economic loss across the world (Baldvin \& Mauro, 2020; Senol \& Zeren, 2020). Researchers estimated that Covid-19 portends greater economic loss relative to the previous crisis. It has been estimated that, at a global spread comparable to the Spanish Influenza, Covid-19 would have more than 80 million deaths (Dhar, Ayittey \& Sarkar, 2020; Ferrantino, Arvis, Constantinescu, Dairabayeva, Gillson, Lee \& Muramatsu, 2020). Just in the week of February 24, 2020, the global stock market lost about 6 trillion USD in wealth (Ozili and Arun, 2020).

The economic impact of epidemics and global financial crises always include a likely fall in stock performance. By March 2020, Covid-19 had caused their greatest one-day fall in many stock market indices. For example, Brazil stock market recorded 48\% fall, 47\% fall in Colombia, 44\% in Greece, $42 \%$ in Norway and 41 in Austria (Alber, 2020; Fernandez, 2020; Kandil-Gokera, Eren \& Karaca, 2020). Surprisingly, stock prices in China remained relatively stable compared to other parts of the world (Xinhua, 2020). This study examines the impact of the Covid-19 pandemic on the Nigerian stock market. Has it caused a structural break in the trend of the Nigeria All Share Index (ASI)? If yes, at what point? What is the extent of the variations in ASI before and after the break? The answers to these questions would help future researchers in econometrics analysis involving the Nigeria ASI by taking cognizance of the structural break resulting from the pandemic.

\section{Literature Review}

Analysis of the impacts of crises on the stock market has been of interest to researchers over time. Impacts of SARS on the stock market have been greatly investigated by studies like Nippani \& Washer (2004); Chen, Jang \& Kim (2007); 
Chen, Chen, Tang \& Huang (2009) and Chen, Lee, Lin, and Chen (2018).

Some studies examined the impact of multiple crises. For example: Ali, Nassir, Hassan, and Abidin (2010) examined the impacts of SARS, The Gulf Crisis, the September 11th, the Invasion of Iraq, and the 2004 Asian Tsunami on the Stock market in Malaysia. Similarly, Wang, Yang and Chen (2013) analysed the impacts of SARS, Enterovirus 71, Dengue Fever, and H1N1 on biotechnology stocks in Taiwan.

There are studies that have examined the impacts of the Covid-19 outbreak. Sansa (2020), for example, analysed the impact of Covid-19 on the financial market in China and the USA using data between March 1 and March 25, 2020 and confirmed significant impacts. He, Liu, Wang and Yu (2020) examined the direct and spill-over effect of COVID-19 on stock markets using daily return data. The authors confirmed that America COVID-19 has a short-term negative impact on stock markets with bidirectional spill-over effects between European/American countries and Asian countries. Of much proximity to the current study was the work of Zeren and Hizarc1 (2020). They analysed the impact of Covid-19 on the financial market in China, France, Spain, South Korea, Italy and Germany and identified the presence of structural break in many stock market indices, in March 2020, using the structural break unit root tests. They also found evidence of co-integration between daily total cases and stock market indices in China, South Korea and Spain but not for France, Italy and Germany. Similarly, Alber (2020) found significant negative impact of Covid-19 on the stock market in China, Spain, France, Italy, USA, and Germany.

\section{Theoretical Framework and Methodology}

Following Perron, 2006 and Kim and Pierre, 2009 formulation, the theoretical foundation for break date identification in this study is the innovation outlier which can be stated as follows:

$$
A S I_{t}=A S I_{t-1}+\alpha+\beta(L)\left(\phi D_{t}\left(T_{b}\right)+\varphi D U_{t}\left(T_{b}\right)+\varepsilon_{t}\right)
$$

Where ASI is the Nigeria's All Share Index

$\alpha$ is the trend parameter

$\beta$ is the break parameter

$L$ indicate lag

$T_{b}$ is the break date

$D_{t}\left(T_{b}\right)=1\left(t=T_{b}\right)$ is an indicator variable that is equal to 1 on the break date and 0 elsewhere.

$D U_{t}\left(T_{b}\right)=1\left(t \geq T_{b}\right)$ is an indicator variable (is) equal to 1 from the break date to the end and 0 otherwise.

$\varepsilon_{t}$ is an independently and identically distributed error terms 
Muideen A. Isiaka, Modinat O. Ogunmolu, Lukuman O. Lamidi, Saheed T. Ogunmolu. Impact of Covid-19 on the Performance of Nigeria's Stock Market

After identifying the break date using equation 1, this study analyses the descriptive statistics before and after the break using mean, median, maximum, minimum, standard deviation, skewness, kurtosis and Jarque-Bera statistics. This study employs the techniques of Autoregressive Integrated Moving Average (ARIMA). It involves determining the values of $\mathrm{p}, \mathrm{q}$ and $\mathrm{d}$ for the series using deduction from Autocorrelation Function (ACF) and Partial Autocorrelation Function (PACF). The ARIMA modeling is based on Box-Jenkins statistical model (Garrett, 2012).

The ARIMA modeling involves testing for the stationarity of the series before and after the break. A time series is said to be stationary if there is no systematic trend in its mean (no trend) and variance, and has no periodic variations. To test the stationarity of the series, the study plots the ACF and PACF of the series and draw out conclusions from the graphs. Also Augumented Dickey Fuller test is used to test the stationarity of the series.

After analysing the ACF, the PACF and the the stationarity test, there may be more that one suggestive models for the series. To select the best model, the selection criteria include: model with the highest number of significant coeffiients, model with the lowest volatility, model with the highest adjusted $\mathrm{R}^{2}$ and model with the lowest information criterion (Akaike Information Criterion - AIC and Schwarz Bayesian Information Criterion - BIC).

Before fitting the best ARIMA model, the study also conducts diagnostic check to ensure that the obtained best model has left no significant information uncaptured. We achieve this by analysing the correlogram of the residuals and check that all the lags in the correlogram are flat (that is, falling within $95 \%$ confidence bound). If this is not the case, the best model is adjusted as suggested by the diagnostic check.

For the Autoregressive model, the current value of the All Share Index (ASI) series is modeled as a function of its past 'p' values, $\left(A S I_{t-1}, A S I_{t-2}, \ldots, A S I_{t-p}\right)$; where 'p' is the number of steps into the past needed to forecast the current value. An autoregressive model of order p, $[\mathrm{AR}(\mathrm{p})]$ could be explicitly written as,

$$
A S I_{t}=\varphi_{1} A S I_{t-1}+\varphi_{2} A S I_{t-2}+\cdots+\varphi_{p} A S I_{t-p}+\varepsilon_{t}
$$

Where $A S I_{t}$ is a stationary series, $\varphi_{1}, \varphi_{2}, \ldots, \varphi_{p}$ are the parameters of the $A R\left(\varphi_{p} \neq 0\right) ; \varepsilon_{t}$ is white noise (error term).

For the Moving Average part, the current value of the series depends on its past shocks or errors. Thus, a Moving Average process of order q [MA(q)] is specified as:

$$
A S I_{t}=\mu+\theta_{1} \varepsilon_{t-1}+\theta_{2} \varepsilon_{t-2}+\cdots+\theta_{q} \varepsilon_{t-q}+v_{t}
$$

Where $\mu$ is the expectation of, $A S I_{t}, \theta_{1}, \ldots, \theta_{q}$ are the parameters and $v_{t}$ is white noise (error term).

The combined ARIMA model is usually referred to as the ARIMA (p,d,q) model 
where $p$ is the order of the autoregressive part, $d$ is the required times of differencing required to achieve stationarity and $\mathrm{q}$ is the order of the moving average part. An Autoregressive Moving Average of order (p, d, q) is given as

$$
\Delta_{d} A S I_{t}=\mu+\sum_{i=1}^{p} \varphi_{i} A S I_{t-i}+\sum_{i=1}^{q} \theta_{i} \varepsilon_{t-i}+\varepsilon_{t}
$$

\section{Results and Findings}

This section contains the presentation and analysis of the results.

\subsection{Identification of Structural Break in ASI Series}

Figure 1 presents the visual representation of the ASI trends. The most significant drop in the values of the series is month 3 of 2020 (March).

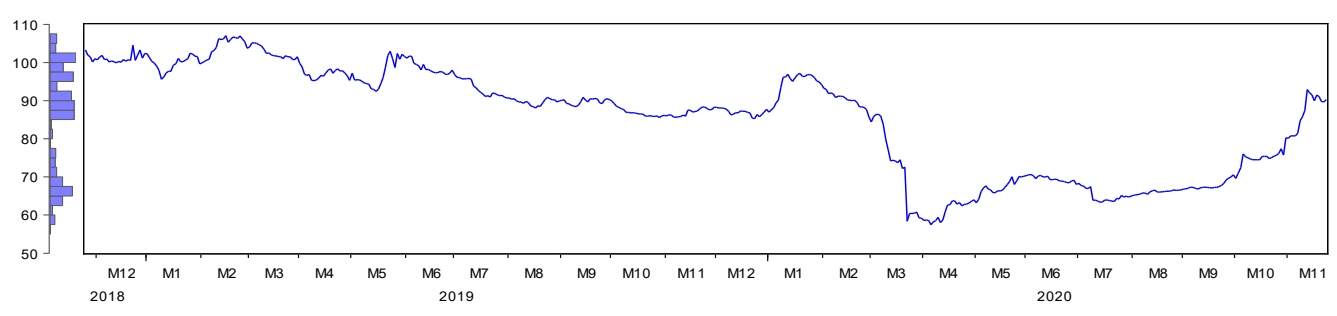

Figure 1. Trend of ASI Series 11/2018-11/2020

Source: Author's Computation

For the period between March and October 2020, the series was consistently below the average value before March 2020. The ASI recovered greatly during early part of November 2020 but started a falling trend again.

\subsection{Break Date Identification}

Table 1 (see Appendix) and Figure 2 contain the results of the formal test for break using the Innovation outlier method described under the methodology.

From Table 1, the probability value of 0.28 and the test critical values of -5.72 , -5.18 and -4.89 for $1 \%, 5 \%$ and $10 \%$ respectively indicate non-stationarity of the ASI series. Based on minimum Dickey-Fuller t-test criterion, the identified break date is March 6, 2020.

The visual representation of the Dickey-Fuller t-statistics minimization for identifying break date is shown in Figure 2. 
Muideen A. Isiaka, Modinat O. Ogunmolu, Lukuman O. Lamidi, Saheed T. Ogunmolu. Impact of Covid-19 on the Performance of Nigeria's Stock Market

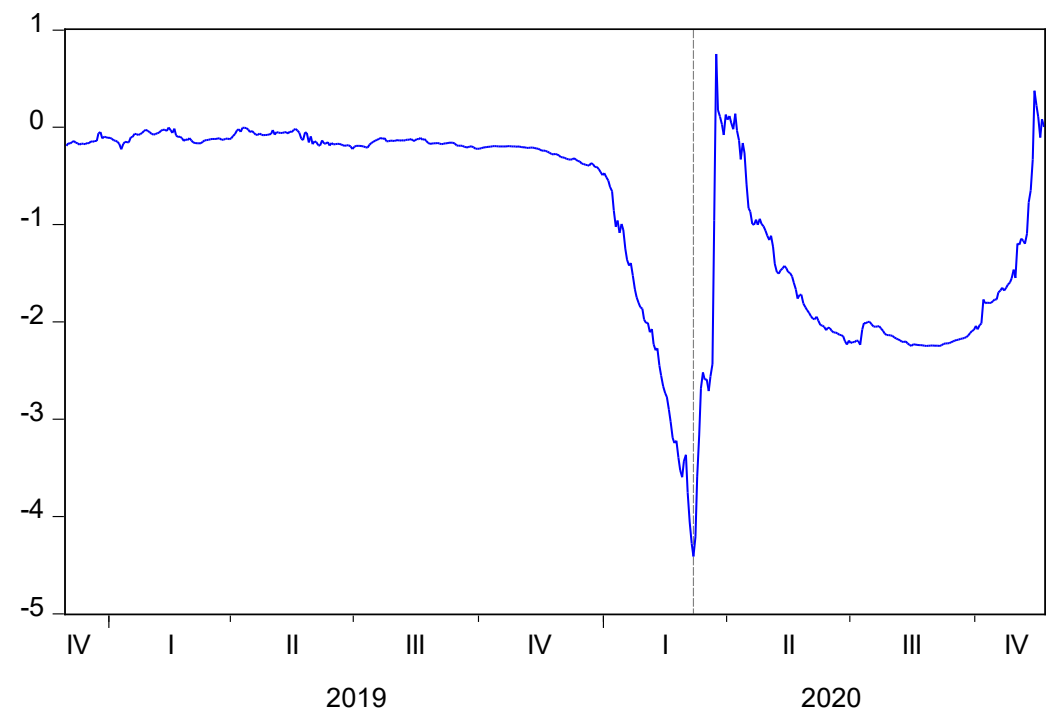

Figure 2. Plot of Dickey-Fuller t-statistic

Source: Author's Computations

\subsection{Descriptive Analysis of ASI (before and after the Break)}

The comparative descriptive analysis, before and after the break, is summarized in Table 2 (see Appendix). It can be observed that the highest value of the index was recorded in the pre-break period and the lowest value was recorded in the postbreak period. Despite the post-break period having a considerably lower number of observations than the pre-break period, the standard deviation statistic indicates that price appears to be more volatile in the post-break period.

The skewness statistic indicates that price has a positively skewed distribution in the pre-break and post-break periods, thus indicating that there is a higher tendency to obtain positive extreme price movement than negative extreme price changes on the Nigeria Stock Exchange. The Kurtosis coefficient indicates price is light-tailed before the break and has a heavy tail in the post-break period. The Jarque-Bera statistic and probability value indicate that the price series is not normally distributed in both the pre-break and post-break periods; Hence the Gaussian normal error distribution cannot be assumed for the series in the two periods. 


\subsection{ARIMA Analysis of ASI before the Break}

\subsubsection{Test of Stationarity (before break)}

The plots of the autocorrelation function (ACF) and the partial autocorrelation function (PACF) are displayed in Figure 3. For the ACF the broken lines are the standard error bounds. The autocorrelation declines very slowly.

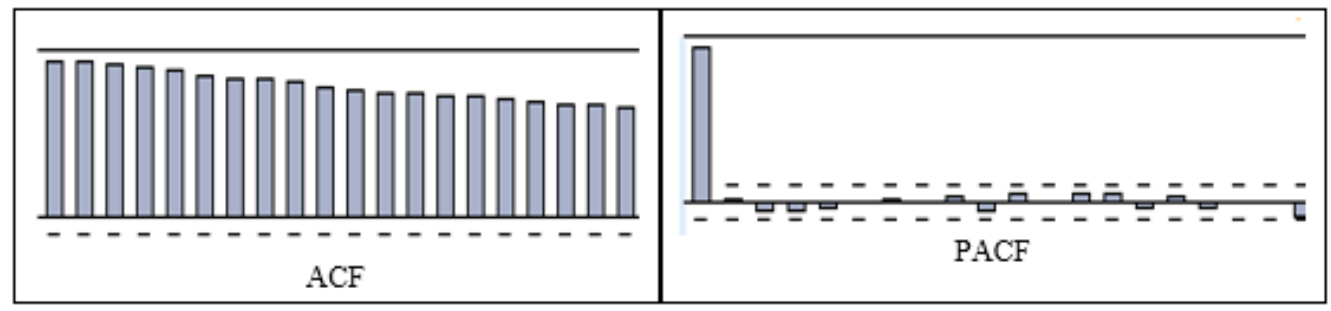

Figure 3. Autocorrelation and Partial Autocorrelation Functions (Before Break)

Source: Author's Computations

The PACF shows that the first lag is very significant while every other one cuts off. Therefore, the series is indicative of a non-stationary series because the decline in the ACF is gradual. To confirm that the ASI series before the break date is integrated of order 1, the stationarity test is performed on the first differenced series. The result is shown in Table 3 (see Appendix). Since the probability value $(0.00)$ is less than $\alpha$-level (0.05), the ASI before break is now stationary after the first difference.

\subsubsection{ARIMA Model Parameterisation (before break)}

The ACF and PACF of the differenced series are shown in Figure 4. The PACF shows significant spikes at lag 3 and lag 12 suggesting an Autoregressive Pattern of order 3 or 12.

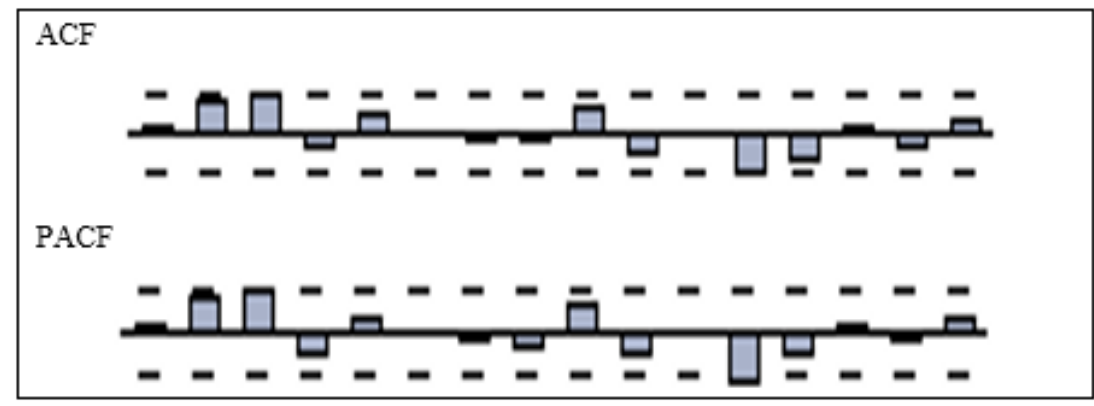

Figure 4. ACF and PACF of D(ASI $\left.{ }_{\text {before }}\right)$

Source: Author's Computations 
Muideen A. Isiaka, Modinat O. Ogunmolu, Lukuman O. Lamidi, Saheed T. Ogunmolu. Impact of Covid-19 on the Performance of Nigeria's Stock Market

Similarly, the ACF also shows significant spikes at lag 3 and 12, then it decays suggesting a Moving Average of order 3 or 12. Thus, possible model fomulations are : $\operatorname{ARIMA}(3,1,3), \operatorname{ARIMA}(3,1,12), \operatorname{ARIMA}(12,1,3)$ and $\operatorname{ARIMA}(12,1,12)$. The results of each model fitted are summarised in Table 4 (see Appendix).

It can be observed from Table 4 that ARIMA $(3,1,12)$ is the most appropriate model with 2 significant coefficients, least volatility of 0.75 , highest adjusted $R^{2}$ of 0.02 , lowest AIC of 2.58 and least BIC of 2.62. In order to be sure that the ARIMA $(3,1,12)$ has left no information uncaptured, the diagnostic analysis involves examining the correlogram of the residuals as shown in Table 5.

Since all the lags present in the correlogram have remained flat within the $95 \%$ confidence bound, then it is concluded that $\operatorname{ARIMA}(3,1,12)$ is indeed the best model for this series.

\subsection{ARIMA Analysis of ASI after the Break}

\subsubsection{Test of Stationarity (after break)}

The PACF shows that the first lag is very significant while every other one cuts off. Therefore, the series is indicative of a non-stationary series because the decline in ACF is gradual. This requires runing a stationarity test.

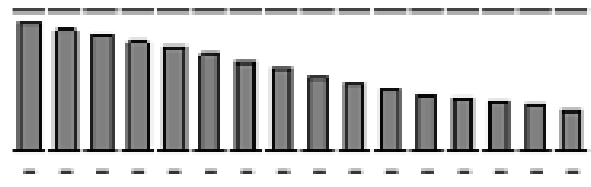

$\mathrm{ACF}$

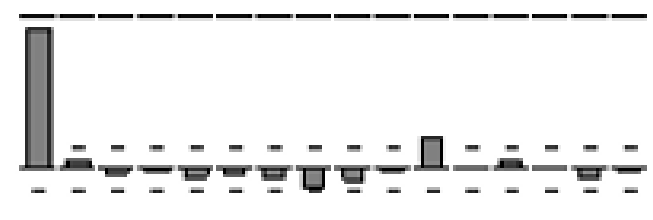

PACF

Figure 5. Autocorrelation and Partial Autocorrelation Functions (After Break)

Source: Author's Computations

To confirm that the ASI series after the break date is integrated of order 1, the stationarity test is performed on the first differenced series. The results is shown in Table 6. Since the p-value $(0.00)$ is less than $\alpha$-level (0.05), we concluded that first difference of ASI after break is now stationary and thus, ASI after break is integrated on order $1(\mathrm{~d}=1)$.

\subsubsection{ARIMA Model Parameterisation (after break)}

The ACF and PACF of the differenced ASI series after the break are shown in Figure 6. The PACF shows a significant spikes at lag 2, lag 7 and lag 9. This suggests an Autoregressive Pattern of order 2, 7 or 9. Similarly, the ACF also suggests a Moving Average of order 2, 7 or 9 . 


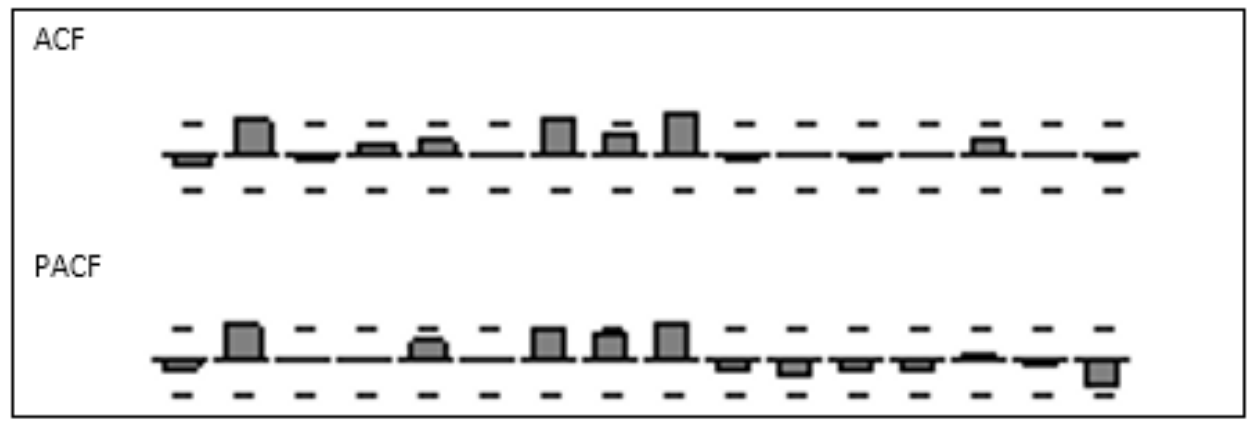

Figure 6. ACF and PACF of D(ASI $\left.I_{\text {after }}\right)$

Source: Author's Computations

The tentative models that can capture the variation in the series are thus: $\operatorname{ARIMA}(2,1,2), \quad \operatorname{ARIMA}(2,1,7), \operatorname{ARIMA}(2,1,9), \operatorname{ARIMA}(7,1,2), \operatorname{ARIMA}(7,1,7)$, $\operatorname{ARIMA}(7,1,9), \operatorname{ARIMA}(9,1,2), \operatorname{ARIMA}(9,1,7)$ and $\operatorname{ARIMA}(9,1,9)$. The results of each of the 9 possible models are summarised in Table 7 (see Appendix).

Following the same guidelines used in identifying the best model earlier, $\operatorname{ARIMA}(7,1,9)$ is selected here as the best model. In order to be sure that the ARIMA $(7,1,9)$ has left no information uncaptured, the diagnostic results are shown in Table 8 (see Appendix). Since there exists a significant spike at lag 8 beyond the $95 \%$ confidence bound for both ACF and PACF, then the model still leaves some information uncaptured and so it is adjusted by adding $\mathrm{AR}(8)$ and MA(8). The two additional models are compared to the initial selected model in Table 9. It would now be concluded with respect to all indications that the model with $\mathrm{AR}(7), \mathrm{MA}(8)$ and $\mathrm{MA}(9)$ is the most appropriate model for this series.

\subsection{ARIMA and Volatility Estimates (before and after break)}

The parameter estimate of the ARIMA models and volatility estimates before and after the break are summarised in Table 10. The ARIMA model for the series before the structural break shows that $\mathrm{ASI}_{t}$ is dependent on an AR and MA process of lags 3 and 12 respectively with parameter estimates of 0.11 and -0.13 respectively. On the other hand, the ARIMA model of the series after the structural break indicates lag 7 for the AR process and lags 8 and 9 for the MA process. Their parameter estimates are 0.19 , 0.24 and 0.26 respectively.

The volatility estimates is 2.02 for the series before the break and 1.92 for after break, indicating that the series before the structural break is more volatile than the series after the break. 
Muideen A. Isiaka, Modinat O. Ogunmolu, Lukuman O. Lamidi, Saheed T. Ogunmolu. Impact of Covid-19 on the Performance of Nigeria's Stock Market

\section{Conclusion}

This study examines the presence of structural break in Nigeria's stock market due to Covid-19. The results of the structural break indicate the presence of a structural break in the series and the break period is identified as March 6,2020. The break date is 8 days from the date of the first confirmed case of Covid-19 in Nigeria (February 27, 2020) and 5 days before the WHO declared Covid-19 as pandemic. This suggests that the Nigerian stock market is sensitive to local materialization of Covid-19, even before it was declared a pandemic.

Further analyses were conducted on the series before and after the break and it became known that despite the post-break period having a considerably lower number of observations than the pre-break period, the standard deviation statistic indicates that ASI appears to be less volatile in the post-break period. Also, it was realized that the highest value of the index was recorded in the pre-break series and the lowest value was recorded in the post-break period.

The ARIMA model for the series before the structural (break) also shows that $A S I_{t}$ is dependent on an AR and MA process of lags 3 and 12 with their estimates 0.11 and -0.13 respectively, whereas the ARIMA model of the series after the structural break indicates lag 7 for the AR process and lags 8 and 9 for the MA process. Their estimates are $0.19,0.24$ and 0.26 respectively.

The volatility estimates indicate that the series before the structural break is more volatile than the series after the break following their estimates 2.02 and 1.92 for the pre-break and post-break periods respectively.

The analysis suggests that while the price indexes on the Nigeria stock market shifted downward on March 6,2020, the risk also decreased. This might suggest that market participants give positive value to government efforts in managing the risk of Covid-19. However, further study that considers sectoral analysis and return series would add valuable contribution to this issue.

\section{References}

1. Alber, N. (2020). The effect of coronavirus spread on stock markets. The case of the worst 6 countries, http://ssrn.com/abstract $=3578080$.

2. Ali, N., Nassir, A. M., Hassan T., \& Abidin, S. Z. (2010). Short-run stock overreaction. Evidence from Bursa Malaysia, International Journal of Economics and Management, 4(2), 319-333

3. Baldvin, R. \& Mauro, B. W. (2020). Mitigating the COVID economic crisis. Act fast and do whatever it takes, CERP Press, UK. 
4. Chen, C. D., Chen, C. C., Tang, W. W. \& Huang, B. Y. (2009). The positive and negative impacts of the SARS outbreak. A case of the Taiwan industries, The Journal of Developing Areas, 43(1), 281-293.

5. Chen, M. H., Jang, S. S., \& Kim, W. G. (2007). The impact of SARS outbreak on Taiwanese hotel stock performance. An event-study approach, Hospitality Management, 26, 200-212.

6. Chen, M. P., Lee, C. C., Lin, Y. H., \& Chen, W. Y. (2018). Did the SARS epidemic weaken the integration of Asian stock markets? Evidence from smooth timevarying cointegration analysis, Economic Research, 31 (1), 908-926.

7. Dhar, B. K., Ayittey, F. A., \& Sarkar, S. M. (2020). Impact of COVID-19 on Psychology among the University Students. Global Challenges, 4(9), 2000038. https:// doi.org/ 10.1002/gch2.202000038

8. Fernandez, N. (2020). Economic effects of coronavirus outbreak (Covid-19) on the world economy. Revised, April 13, 2020. Version 2.0. http://ssrn.com/ abstract $=3557504$.

9. Ferrantino, M. J., Arvis, J. F., Constantinescu, I. C., Dairabayeva, K. S., Gillson, I. J. D., Lee, W., \& Souza Muramatsu, K. (2020). COVID-19 Trade Watch. The World Bank, 148956, 1- 34

10. Garrett, L. C. (2012) Using Box-Jenkins modeling techniques to forecast future disease burden and identify disease aberrations in public health surveillance report. Western Michigan University, Dissertations 106. https://scholarworks.wmich. edu/dissertations/106.

11. Gunay, S. (2020). A new form of financial contagion: Covid-19 and stock market responses, http://ssrn.com/abstract=3585069.

12. He, Q., Liu, J., Wang, S. \& Yu, J. (2020) The impact of COVID-19 on stock markets. Economic and Political Studies, 8(3), 275-288.

13. Kandil-Gokera, I. E., Eren, B.S. \& Karaca, S.S. (2020) The impact of the COVID - 19 (Coronavirus) on The Borsa Istanbul Sector Index Returns: An Event Study. Gaziantep University Journal of Social Sciences, 2020 Special Issue, 14-41.

14. Kim, D. and Pierre P. (2009). Unit root tests allowing for a break in the trend function at an unknown time under both the null and alternative hypotheses, Journal of Econometrics, 148, 1-13.

15. Nippani, S. \& Washer, K. M. (2004). SARS: A non-event for affected countries' stock markets? Applied Financial Economics, 14, 1105-1110.

16. Ozili, P. K., \& Arun, T. (2020). Spillover of COVID-19: Impact on the global economy. Unpublished Manuscript. https://ssrn.com/abstract=3562570

17. Perron, P. (2006). Dealing with Structural Breaks, in Palgrave Handbook of Econometrics, Vol. 1: Econometric Theory, K. Patterson and T. C. Mills (eds.), Palgrave 
Muideen A. Isiaka, Modinat O. Ogunmolu, Lukuman O. Lamidi, Saheed T. Ogunmolu. Impact of Covid-19 on the Performance of Nigeria's Stock Market

Macmillan, 278-352.

18. Şenol, Z. \& Zeren, F. (2020). Coronavirus (COVID-19) and stock markets. The effects of pandemic on the global economy. Eurasian Journal of Researches in Social and Economics, 7(4), 1-16.

19. Wang, T. H., Yang F. J. \& Chen L. J. (2013). An investor's perspective on infectious diseases and their influence on market behaviour, Journal of Business Economics and Management, 14(1), 112-127.

20. Xinhua, H. (2020). China financial markets remains stable amid Covid-19 impact, https://www.chinadailyhk.com/article/125145.

21. Zeren, F. \& Hizarc1, A. E. (2020). The impact of Covid-19 coronavirus on stock markets. Evidence from selected countries, Muhasebe ve Finans İncelemeleri Dergisi, 3(1), 78-84.

\section{Appendix}

Table 1

\section{E-View Results of Break Date}

\begin{tabular}{|c|c|c|c|}
\hline \multicolumn{4}{|c|}{$\begin{array}{l}\text { Break Specification: Trend and intercept } \\
\text { Break Type: Innovational outlier } \\
\text { Break Date: 3/06/2020 } \\
\text { Break Selection: Minimize Dickey-Fuller } \\
\text { Lag Length: } 0 \text { (Automatic - based on Sch }\end{array}$} \\
\hline & & t-Statistic & Prob.* \\
\hline \multicolumn{2}{|c|}{ Augmented Dickey-Fuller test statistic } & -4.409965 & 0.2802 \\
\hline \multirow[t]{3}{*}{ Test critical values: } & $1 \%$ level & -5.719131 & \\
\hline & $5 \%$ level & -5.175710 & \\
\hline & $10 \%$ level & -4.893950 & \\
\hline
\end{tabular}

Source: Author's Computations 


\section{Comparative Descriptive Statistics}

\begin{tabular}{|c|c|c|}
\hline Statistic & Before break & After break \\
\hline Mean & 94.46833 & 69.29235 \\
\hline Median & 95.13000 & 67.24000 \\
\hline Maximum & 107.0000 & 92.84000 \\
\hline Minimum & 84.38000 & 57.41000 \\
\hline Std. Dev. & 6.115782 & 7.405770 \\
\hline Skewness & 0.159280 & 1.308003 \\
\hline Kurtosis & 1.758574 & 4.757921 \\
\hline Jarque-Bera & 22.92822 & 77.40063 \\
\hline Probability & 0.000011 & 0.000000 \\
\hline Observations & 335 & 187 \\
\hline
\end{tabular}

Source: Author's Computations

Table 3

Unit Root Test on First Differenced Series (Before Break)

\begin{tabular}{|l|c|c|c|}
\hline & & t-Statistic & Prob. $^{*}$ \\
\hline \multicolumn{2}{|l|}{ Augmented Dickey-Fuller test statistic } & -17.84841 & 0.0000 \\
\hline Test critical values: & $1 \%$ level & -3.449797 & \\
\hline \multirow{2}{*}{} & $5 \%$ level & -2.870004 & \\
\cline { 2 - 4 } & $10 \%$ level & -2.571349 & \\
\hline
\end{tabular}

Source: Author's Computations

Table 4

Estimates of Alternative ARIMA Model for ASI ${ }_{\text {before }}$

\begin{tabular}{|c|c|c|c|c|}
\hline D(ASI) & $\begin{array}{c}\text { ARIMA } \\
\mathbf{( 3 , 1 , 3 )}\end{array}$ & $\begin{array}{c}\text { ARIMA } \\
\mathbf{( 3 , 1 , 1 2 )}\end{array}$ & $\begin{array}{c}\text { ARIMA } \\
\mathbf{( 1 2 , 1 , 3 )}\end{array}$ & $\begin{array}{c}\text { ARIMA } \\
\mathbf{( 1 2 , 1 , 1 2 )}\end{array}$ \\
\hline Significant coeffiients & 2 & 2 & 2 & 1 \\
\hline Volatility & 0.752200 & 0.750698 & 0.751093 & 0.756526 \\
\hline Adjusted R & 0.015158 & 0.017124 & 0.016607 & 0.009494 \\
\hline AIC & 2.578111 & 2.575775 & 2.576238 & 2.583899 \\
\hline SBIC & 2.623753 & 2.621418 & 2.621881 & 2.629541 \\
\hline
\end{tabular}

Source: Author's Computations 
Muideen A. Isiaka, Modinat O. Ogunmolu, Lukuman O. Lamidi, Saheed T. Ogunmolu. Impact of Covid-19 on the Performance of Nigeria's Stock Market

Table 5

Model Diagnostic for ARIMA $(3,1,12)$

\begin{tabular}{|c|c|c|c|c|c|c|}
\hline Autocorrelation & Partial Correlation & & $A C$ & PAC & Q-Stat & Prob \\
\hline $1 \mid 1$ & $1 \mid 1$ & 1 & 0.007 & 0.007 & 0.0184 & \\
\hline 1 & I & 2 & 0.082 & 0.081 & 2.2656 & \\
\hline 1 & 1 & 3 & 0.001 & -0.000 & 2.2659 & 0.132 \\
\hline 11 & 11 & 4 & -0.040 & -0.047 & 2.8187 & 0.244 \\
\hline 11 & 1 & 5 & 0.041 & 0.042 & 3.3892 & 0.335 \\
\hline 11 & 11 & 6 & -0.017 & -0.011 & 3.4898 & 0.479 \\
\hline 11 & 1 & 7 & 0.008 & 0.001 & 3.5123 & 0.622 \\
\hline 11 & 1 & 8 & -0.043 & -0.043 & 4.1366 & 0.658 \\
\hline 10 & 19 & 9 & 0.088 & 0.093 & 6.8291 & 0.447 \\
\hline 1 & 1 & 10 & -0.053 & -0.051 & 7.7853 & 0.455 \\
\hline $1 \mid 1$ & 11 & 11 & -0.001 & -0.013 & 7.7856 & 0.556 \\
\hline 1 & 1 & 12 & 0.002 & 0.007 & 7.7873 & 0.650 \\
\hline 1 & 11 & 13 & -0.074 & -0.062 & 9.6866 & 0.559 \\
\hline 11 & 11 & 14 & 0.027 & 0.015 & 9.9423 & 0.621 \\
\hline 111 & 11 & 15 & -0.034 & -0.018 & 10.348 & 0.665 \\
\hline 11 & 11 & 16 & 0.025 & 0.021 & 10.575 & 0.719 \\
\hline
\end{tabular}

Source: Author's Computations

Table 6

Unit Root Test on First Differenced Series (After Break)

\begin{tabular}{lccc}
\hline \hline & t-Statistic & Prob. $^{*}$ \\
\hline \hline Augmented Dickey-Fuller test statistic & -14.27122 & 0.0000 \\
\hline Test critical values: & 1\% level & -3.465780 & \\
& $5 \%$ level & -2.877012 & \\
& 10\% level & -2.575097 & \\
\hline \hline
\end{tabular}

Source: Author's Computations

Table7

Estimates of Alternative ARIMA Model for ASI $_{\text {after }}$

\begin{tabular}{|l|c|c|c|c|c|c|c|c|c|}
\hline D(1) ASI & $\begin{array}{c}\text { ARIMA } \\
(\mathbf{2 , 1 , 2 )}\end{array}$ & $\begin{array}{c}\text { ARIMA } \\
\mathbf{( 2 , 1 , 7 )}\end{array}$ & $\begin{array}{c}\text { ARIMA } \\
\mathbf{( 2 , 1 , 9 )}\end{array}$ & $\begin{array}{c}\text { ARIMA } \\
\mathbf{( 7 , 1 , 2 )}\end{array}$ & $\begin{array}{c}\text { ARIMA } \\
\mathbf{( 7 , 1 , 7 )}\end{array}$ & $\begin{array}{c}\text { ARIMA } \\
\mathbf{( 7 , 1 , 9 )}\end{array}$ & $\begin{array}{c}\text { ARIMA } \\
\mathbf{( 9 , 1 , 2 )}\end{array}$ & $\begin{array}{c}\text { ARIMA } \\
\mathbf{( 9 , 1 , 7 )}\end{array}$ & $\begin{array}{c}\text { ARIMA } \\
\mathbf{( 9 , 1 , 9 )}\end{array}$ \\
\hline $\begin{array}{l}\text { Significant } \\
\text { coeffiients }\end{array}$ & 0 & 1 & 2 & 1 & 0 & 2 & 2 & 1 & 2 \\
\hline Volatility & 2.0997 & 2.0640 & 2.0294 & 2.0597 & 2.0748 & 2.0157 & 2.0235 & 2.0148 & 2.0304 \\
\hline Adjusted R & 0.0123 & 0.0291 & 0.0454 & 0.0311 & 0.0240 & 0.0517 & 0.0481 & 0.0522 & 0.0449 \\
\hline AIC & 3.6230 & 3.6064 & 3.5905 & 3.6045 & 3.6132 & 3.5847 & 3.5880 & 3.5844 & 3.5965 \\
\hline SBIC & 3.6924 & 3.6758 & 3.6599 & 3.6739 & 3.6825 & 3.6541 & 3.6574 & 3.6538 & 3.6659 \\
\hline
\end{tabular}

Source: Author's Computations 


\section{Table 8}

Model Diagnostic for ARIMA $(7,1,9)$

\begin{tabular}{|c|c|c|c|c|c|c|}
\hline Autocorrelation & Partial Correlation & & $A C$ & PAC & Q-Stat & Prob \\
\hline IL I & I I & 1 & -0.087 & -0.087 & 1.4208 & \\
\hline 1 & 16 & 2 & 0.126 & 0.119 & 4.4145 & \\
\hline 1 & 1 & 3 & -0.022 & -0.003 & 4.5101 & 0.034 \\
\hline I 1 & 11 & 4 & 0.037 & 0.020 & 4.7664 & 0.092 \\
\hline 1 & 1 & 5 & 0.045 & 0.053 & 5.1540 & 0.161 \\
\hline 11 & $1 \mid 1$ & 6 & 0.021 & 0.022 & 5.2396 & 0.264 \\
\hline 1 & 11 & 7 & -0.018 & -0.026 & 5.3028 & 0.380 \\
\hline 1 & 1 & 8 & 0.151 & 0.147 & 9.7947 & 0.134 \\
\hline 1 & 11 & 9 & 0.002 & 0.028 & 9.7953 & 0.200 \\
\hline I 1 & 11 & 10 & 0.025 & -0.013 & 9.9213 & 0.271 \\
\hline 1 & 11 & 11 & -0.030 & -0.029 & 10.097 & 0.343 \\
\hline 11 & 11 & 12 & -0.015 & -0.028 & 10.143 & 0.428 \\
\hline 11 & 11 & 13 & -0.012 & -0.026 & 10.172 & 0.515 \\
\hline 1 & 1 | & 14 & 0.034 & 0.031 & 10.409 & 0.580 \\
\hline 1 & 11 & 15 & -0.026 & -0.012 & 10.544 & 0.649 \\
\hline 1 & I 1 & 16 & -0.054 & -0.087 & 11.139 & 0.675 \\
\hline
\end{tabular}

Source: Author's Computations

Table 9

Estimates of the adjusted ARIMA model

\begin{tabular}{|l|c|c|c|}
\hline \multicolumn{1}{|c|}{ D(1) Price } & ARIMA (7,1,9) & AR(7) AR(8) MA(9) & AR(7) MA(8) MA(9) \\
\hline $\begin{array}{l}\text { Significant } \\
\text { coefficients }\end{array}$ & 2 & 3 & 3 \\
\hline Volatility & 2.01586 & 1.956705 & 1.919205 \\
\hline Adjusted R & 0.05173 & 0.074475 & 0.092212 \\
\hline AIC & 3.58472 & 3.567924 & 3.551448 \\
\hline SBIC & 3.65409 & 3.654638 & 3.638162 \\
\hline
\end{tabular}

Source: Author's Computations

Table 10

Results of ARIMA Model and Volatility Estimate

\begin{tabular}{|c|c|c|}
\hline Period & ARIMA model & $\begin{array}{c}\text { Volatility } \\
\text { Estimate }\end{array}$ \\
\hline Before break & $Y_{t}=-0.050710+0.110941_{t-3}-0.127324 \varepsilon_{t-12}$ & 2.01586 \\
\hline After break & $Y_{t}=-0.004032+0.190533_{t-7}+0.240122 \varepsilon_{t-8}+0.264053 \varepsilon_{t-9}$ & 1.919205 \\
\hline
\end{tabular}

Source: Author's Computations 